\title{
RFID-GSM Autonomous Car Washing System
}

\author{
K. Vidyasagar \\ Dept. of ECE, SSIT \\ Sathupally, T.S, India.
}

\author{
R. Ram Prasad \\ Dept. of ECE, SSIT \\ Sathupally, T.S, India.
}

\author{
P. Nagasekhar \\ Dept. of ECE, SSIT \\ Sathupally, T.S, India.
}

\begin{abstract}
Automation of the process is having its own significance with the advancement of science and technology. Human interpretation may influence to produce faulty results. Now-adays the cost of time is also influencing on the schedule of the human being. This paper focused to develop a methodology implemented as prototype working model. Conveyor belt mechanism is introduced to transfer the car from entry point to the work station. IR sensor technology is used to sense the entry level detection of the car to be washed and at the workstation to initiate the washing process. A circular disc mounted to the shaft of the Johnson geared motor used as base to hold the car for washing. The washing process is enabled by using sprinkler and dryer mechanism. A dust particle detection sensor used to trace the dirty surface on any location of the car. The Zero signal from the sensor causes to open the exit level of the car. An RFID-GSM technology is incorporated to dispatch the car for delivery and the washing status completion is informed to the car owner using GSM technology. The results obtained with the proposed methodology enabled to meet the challenges in car washing system.
\end{abstract}

\section{Keywords}

IR sensors, RFID, GSM, Car washing

\section{INTRODUCTION}

Automation process for car washing system is significantly proven mechanism for time management personalities and interested on reliability in working condition. Manual water servicing is laborious, time consuming and human errors may lead to imperfection in work progress. The technology should suit to the applications of the individual. Embedded systems will play a vital role in automation process. Supervisory control and data acquisition may also be employed for car automation system. Using the RFID Technology Wrong identification of car can be avoided. The proposed implemented mechanism is proven to be the best suited for automation of car washing system.

\section{LITERATURE SURVEY}

This paper describes the automatic car washing system by imparting the micro controller to process the operations. GSM Technology is used to send the information of the process to the car owner [1].

This paper adopted and RFID technology for car washing system [2].

This paper aims to demonstrate the water resource to wash the car. Water contamination water recycling system is focused for modern car washing system [3].

This paper used a programmable logic controller (PLC) for automate the car washing system. This paper also focused to reduce the cost and to improve the operating frequency by implementing the PLCS [4] [6].

This paper used PIC 16F778A micro controller for car washing system [5] [7].

Conveyer belt mechanism is developed by using PLCs for automatic car washing system [8].

\section{HARDWARE IMPLEMENTATION}

Hardware circuit design is organized into two units.
1. Washing process unit
2. Delivery unit.

\subsection{Washing process unit}

Two control units are designed for regulating the conveyor belt mechanism and car detection system. The conveyer belt mechanism is enabling by driving wheel. The driven wheel follows the driving wheel. The conveyer belt is used to carry the car to be washed from entry point to the washing unit. Two solid state relays are used to enable the motor assembly. Two IR Sensors are implanted at the entry point of the conveyer belt and entry point of the washing unit. AT 89S52 microcontroller is used to regulate this process.

Another control unit is designed using AT 89S52 microcontroller to enable and regulate the washing process. This process consists of 1. Car base rotating mechanism, 2 . Water sprinkler mechanism,3. Dryer and dust particle detection mechanism. The car to be washed is released from conveyer belt to the disk automatically. The IR sensor 2 at the entry point of the washing system enable to rotate the disk and causes to drive the sprinkler mechanism. The sprinkler is 'on' until the dust particle sensor detects zero signals. Then the dryer setup is enabling into function. A delay of $300 \mathrm{sec}$ is considered to keep the dryer on.

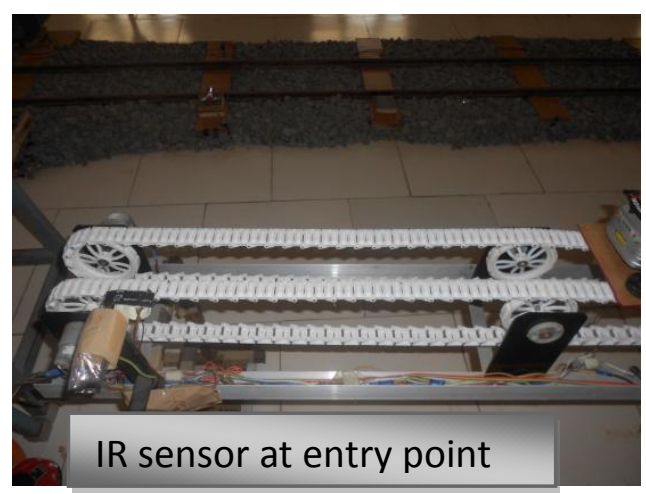

Fig 3.1 IR sensor at the entry point of the conveyer belt 


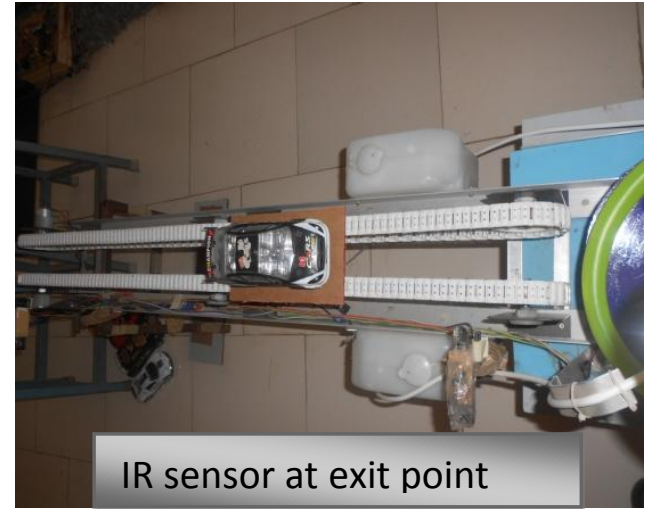

Fig 3.2 Conveyer belt mechanism and IR sensor assembly

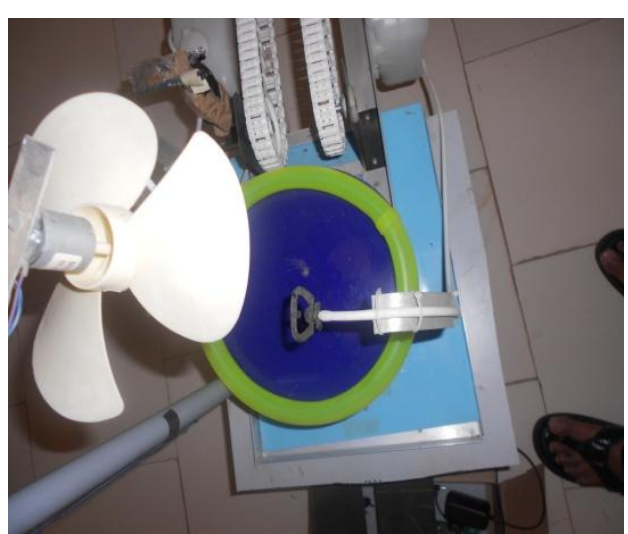

Fig 3.3 Car Washing unit

\subsection{Delivery unit}

An RF ID reader is mounted to each car. After the car washing process is finished, at the delivery stage of the control unit RFID reader detects the identification code of the washed car. The signal from the RFID Reader is fed as an input signal to the controller. ARM 7 microcontrollers is used as a controller. Global system for mobile communication (GSM) is interfaced to the ARM 7 microcontroller to send the wash completed message to the concerned owner.

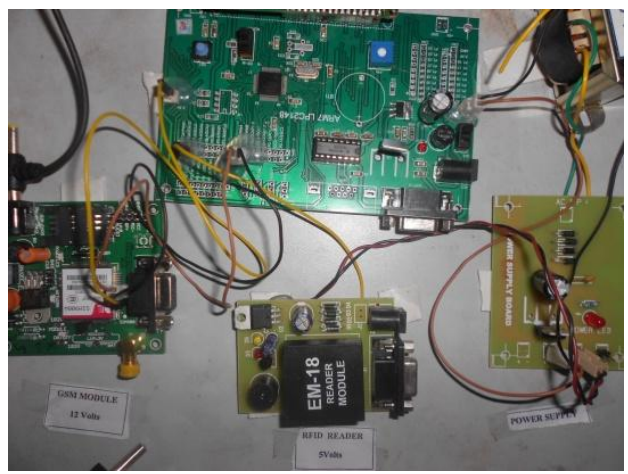

Fig 3.4 Control unit for car delivery system

\subsection{IR Sensor}

IR sensor consists of Transmitter and receiver. Photo diode acts as a receiver. IR Transmitter emits the Infrared radiation continuously on the conveyer belt. If any car on the conveyer belt is detected the Infrared light reflects onto the photo diode.
This signal is interfaced to AT 89S52 Microcontroller as an input signal. The signals from the IR sensors used to enable the conveyer belt mechanism and the washing unit.

The IR sensor at the transmitter transmits continuous IR rays.

The output terminal of the IR receiver varies with respect to the received IR rays. The total three feet length of scaled car belt is organized into two zones. One for source and other one is destination. Two IR sensors are positioned at starting and end of the belt to detect the car. These sensors will function in association with the state of entry and exit of the car status. The signal conversion is not considered since the output signal is an order of digital form. The output signal is interfaced to the encoder (HT- $12 \mathrm{E}$ ) for converting parallel data into serial data using AT89S52 microcontroller. The encoder interfaced to the microcontroller is shown in Fig 1

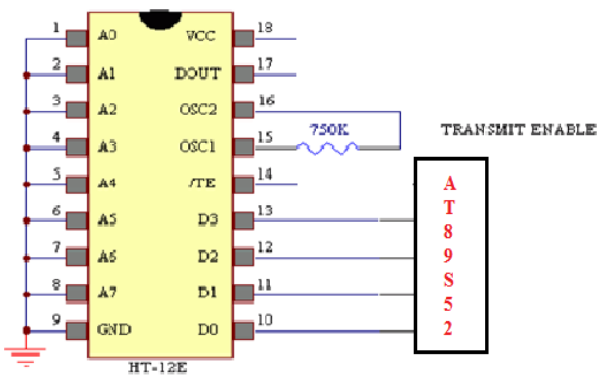

Fig 3.5 Simulated circuit of encoder interfaced to micro controller

\section{IMPLEMENTED ALGORITHAM}

Step1 : Initialize the ports.

Control Unit 1

Port0_1 equate with sensor 1

Port0_2 equate with sensor 2

Port0_4 equate with dust sensor

Port3_0 equate with motor 1

Port3_1 equate with motor 2

Port3_2equate with LCD

Port3_3 equate with water sprinkler

Port3_4 equate with dry fan

Control unit 2

Port $0 \_3$ equate with RFID Reader

Port 3_3 equate with GSM

Step2: read port 0_1

If

The voltage logic level is $\neq$ ' 1 '

Then repeat step 2

Else

Enable the motor driving system

Step3: Read port0_2

If

The voltage logic level is $\neq$ ' 1 '

Then repeat step 3 
Else enable the sprinkler system

Step4: Output Logic '1' on port 3_1

If

The relay is off to rotate the car base

Then

Repeat step 4

Else

Go to step 5

Step 5: Read port 0_4

If

The voltage logic level is $=$ ' 0 '

Then

Disable the sprinkler system, go to step 6

Else

Keep the sprinkler on

Step 6: Enable the dryer system

Step 7: Read port $0 \_3$

$$
\begin{aligned}
& \text { If } \\
& \text { Logic level is } \neq \text { ' } 1 \text { ' } \\
& \text { Then repeat step } 6 \\
& \text { Else } \\
& \text { Output logic ' } 1 \text { ' on port } 3 \_3
\end{aligned}
$$

Step8: Send SMS to car owner.

\section{RESULTS AND ANALYSIS}

The time taken to move the car to be washed from entry point to the washing unit is measured with load and without load condition. So that, the velocity of the conveyer belt is estimated in order to know the driving speed of the system. The total time recorded for completion of the car washing is also recorded for various cars. Fig 5.1 and Fig 5.2 represents the load applied and without load applied on the conveyer belt. Total time consumed to complete the washing operation $=$ Time at conveyer belt + Time at washing unit + delay.

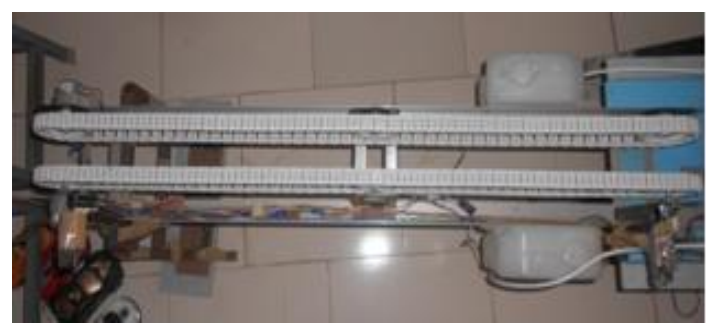

Fig 5.1Conveyer belt speed without car load

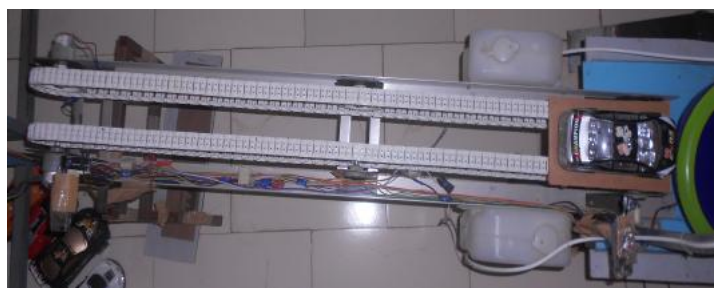

Fig 5.2 Conveyer belt speed with car load

\begin{tabular}{|c|l|c|c|c|c|}
\hline S.No & $\begin{array}{l}\text { Type } \\
\text { of Car }\end{array}$ & \multicolumn{2}{|c|}{$\begin{array}{r}\text { Time taken from } \\
\text { entry point to } \\
\text { exit point (sec) }\end{array}$} & $\begin{array}{l}\text { Velocity } \\
\text { M/Sec }\end{array}$ & $\begin{array}{l}\text { Distance } \\
\text { travelled } \\
\text { (M) }\end{array}$ \\
\cline { 2 - 4 } 1 & $\begin{array}{l}\text { Wight } \\
\text { weight } \\
\text { car }\end{array}$ & $\begin{array}{c}\text { Without } \\
\text { load }\end{array}$ & 12 & 0.1082 & 1.515 \\
\hline 2 & $\begin{array}{l}\text { Heavy } \\
\text { weight } \\
\text { car }\end{array}$ & 18 & 10 & 0.0841 & 1.515 \\
\hline
\end{tabular}

Table 1 The velocity of the conveyer belt with load and without load

\begin{tabular}{|c|l|c|c|c|c|}
\hline S.NO & $\begin{array}{l}\text { Type of } \\
\text { car }\end{array}$ & $\begin{array}{l}\text { Time at } \\
\text { conveyer(sec) }\end{array}$ & $\begin{array}{l}\text { Time } \\
\text { at } \\
\text { wash } \\
\text { unit } \\
(\mathrm{sec})\end{array}$ & $\begin{array}{l}\text { Delay } \\
\text { time } \\
5 \mathrm{sec}\end{array}$ & $\begin{array}{l}\text { Total } \\
\text { time } \\
(\mathrm{sec})\end{array}$ \\
\hline 1 & Dirty & 15 & 10 & 5 & 20 \\
\hline 2 & $\begin{array}{l}\text { Moderate } \\
\text { ly dirty }\end{array}$ & 17 & 14 & 5 & 36 \\
\hline 3 & $\begin{array}{l}\text { Heavy } \\
\text { dirty }\end{array}$ & 20 & 27 & 5 & 52 \\
\hline
\end{tabular}

Table 2 Total time estimated for various dirty conditions of the car

\section{CONCLUSION}

The developed concept is implemented on prototype working model to test various car washing conditions. The results obtained enabled us to implement the same concept for real time applications. So that, by implementing the proposed mechanism improper washing of the car with manual operation may be eliminated. Considerable time is also reduced to complete the operation. In future fuzzy logic concepts proposed to be implemented using ARM processors.

\section{ACKNOWLEDGMENTS}

The authors like to express sincere thanks to the management and principal of Sai Spurthi Institute of Technology for providing the fund and necessary infrastructure. And also thank to Mr. Prassanna Kumar in charge of Radio frequency department Sak informatics.

\section{REFERENCES}

[1] Akilandeswari.K , Haripriya.J, et.al," Implementation of Smart Car Washing Using GSM PLC" IJIRSTE, volume 3(issue 3), March 204. 
[2] Gurjot Singh Gaba, Nancy Gupta,et.al," Intelligent Cars using RFID Technology" IJSER, Volume 3, Issue 7, June 2012.

[3] H. Janik, A. Kupiec," Trends in Modern Car Washing" Polish J. of Environ. Stud. Vol. 16, No. 6 (2007).

[4] Amir Hossein Daei Sorkhabi, Bita Khazini," Manufacturing of Full Automatic Carwash Using with Intelligent Control Algorithms" International Journal of Mechanical, Aerospace, Industrial and Mechatronics Engineering Vol:7, No:3, 2013.

[5] Nader Barsoum, Izam Faizan Bin Moidi," DC Motor Speed Control Using SMS Application" Intelligent Control and Automation, 2014, 5, 205-212.
[6] G.Subramanian K. Tharani Raja," Simulation of Automatic Car Washing Using PLC", IJSRD International Journal for Scientific Research \& Development| Vol. 3, Issue 01, 2015.

[7] N. M. Z. Hashim, M. H. A. Halim.et.al, Vehicle Security System Using Zigbee" International Journal of Scientific and Research Publications, Volume 3, Issue 9, September 2013.

[8] Mr. Abhishek Pansare, Ms. Priyanka Yadav," PLC Based Automatic Car Washing System" International Journal of Advance Engineering and Research Development Volume 2, Issue 4, April -2015. 